Article

\title{
Comparison of ORC Turbine and Stirling Engine to Produce Electricity from Gasified Poultry Waste
}

Franco Cotana $^{1, \dagger}$, Antonio Messineo ${ }^{2, \dagger}$, Alessandro Petrozzi ${ }^{1, \dagger, *}$, Valentina Coccia ${ }^{1}$, Gianluca Cavalaglio ${ }^{1}$ and Andrea Aquino ${ }^{1}$

1 CRB, Centro di Ricerca sulle Biomasse, Via Duranti sn, 06125 Perugia, Italy;

E-Mails: cotana@crbnet.it (F.C.); coccia@crbnet.it (V.C.); cavalaglio@crbnet.it (G.C.); aquino@crbnet.it (A.A.)

2 Università degli Studi di Enna "Kore" Cittadella Universitaria, 94100 Enna, Italy;

E-Mail: messineo.ingegneria@gmail.com

$\dagger$ These authors contributed equally to this work.

* Author to whom correspondence should be addressed; E-Mail: petrozzi@crbnet.it; Tel.: +39-075-585-3806; Fax: +39-075-515-3321.

Received: 25 June 2014; in revised form: 5 August 2014 / Accepted: 12 August 2014 /

Published: 28 August 2014

\begin{abstract}
The Biomass Research Centre, section of CIRIAF, has recently developed a biomass boiler ( $300 \mathrm{~kW}$ thermal powered), fed by the poultry manure collected in a nearby livestock. All the thermal requirements of the livestock will be covered by the heat produced by gas combustion in the gasifier boiler. Within the activities carried out by the research project ENERPOLL (Energy Valorization of Poultry Manure in a Thermal Power Plant), funded by the Italian Ministry of Agriculture and Forestry, this paper aims at studying an upgrade version of the existing thermal plant, investigating and analyzing the possible applications for electricity production recovering the exceeding thermal energy. A comparison of Organic Rankine Cycle turbines and Stirling engines, to produce electricity from gasified poultry waste, is proposed, evaluating technical and economic parameters, considering actual incentives on renewable produced electricity.
\end{abstract}

Keywords: biomass; Organic Rankine Cycle turbine; Stirling engine; gasifier 


\section{Introduction}

The recent regulation for environmental objectives formalized by the EU until 2030 introduces a new reduction target for domestic Greenhouse Gas (GHG) emissions of 40\%, compared to the 1990s, to be shared between the Emissions Trading System (ETS) and non-ETS sectors. It will be accompanied by a coherent headline target at a European level for renewable energy of at least $27 \%$, with flexibility for Member States to set national objectives [1]. Since the establishment of strategic objectives for 2030 in terms of energy efficiency and renewable energy development is still in preparation, the objectives laid down for the 2020s are actually in force [2]. A great contribution in renewable energy is provided from biomass. The whole energy derived from biomass is actually over $60 \%$ of the total renewable energy produced in Europe. In Italy the percentage is higher than 50\%, and in the forecast scenarios for 2030 and 2050 this value is still intended to remain over $40 \%$ [3].

The biomass potential, including the residual biomass, such as zootechnical manures, are reported in a census elaborated by the Biomass Research Centre (CRB) of the University of Perugia, related to the Region Umbria, defining a potential of available biomass of approximately 400,000 tons/year (forest residues, agricultural resources and manure) [4]. Currently, biomass from farms and livestock is disposed with high costs for the owners and the environmental impacts are negative; however, these matters could form the basis for the production of energy, both thermal and electrical, to supply farm needs. Incentives derived from the dispatching of electricity produced from biomass can contribute, in a context of generalized crisis of the rural world, to jump-start the competitiveness of agro-zootechnical companies.

An interesting case of study is the biomass energy enhancement for Combined Heat and Power generation (CHP). Basically, this application includes a biomass primary conversion to hot water, steam, gaseous, or liquid by-products; and a subsequent technology to convert them to final heat and power. The most widely used combination is the direct combustion of biomass coupled with traditional steam turbine technologies, but only for large and medium scale biomass-fueled CHP systems [5-7]. For residential and small commercial applications, the useful sizes are small-scale and micro-scale CHP systems. Although they ensure energy savings and environmental benefits, the high initial costs and long payback period are the main obstacles for their large-scale diffusion [8].

Instead, the direct combustion of biomass, some other conversion technologies are based on gasification or pyrolysis, where a solid fuel is converted into a combustible gas, which can be burnt by boilers, internal combustion engines, or gas turbines to produce heat and power [5].

Regarding the energy enhancement of poultry manure, more technical and environmental problems emerged during the feasibility primary research activities. Firstly, the anaerobic digestion of poultry manure is not efficient due to the high content of nitrogen in the biomass, releasing ammonia that inhibits the metabolic activities of the bacteria for the biogas production [9,10]. Furthermore, the anaerobic digestion of the droppings does not solve the problem of the nitrogen content unless the digested matter is subjected to specific treatments with processing costs that are not negligible [11].

The direct combustion of biomass is not allowed due to the high content of nitrogen in poultry manure, causing the production of exhaust gases rich in high percentage of nitrogen oxides, ammonia, and hydrogen cyanide [12], with the risk of emissions limits exceeding and to gain the plant authorization in accordance with regulations in case of waste burning [13]. 
Two applied technologies are hereunder analyzed about the coupling of small-scale biomass-fuelled CHP systems: the Organic Rankine Cycle (ORC) turbines and Stirling engines. A comparison of ORC turbines and Stirling engines to produce electricity from gasified poultry waste is proposed in this work.

The ORC turbine is an advanced power generation technology, based on organic chemicals with favorable thermodynamic properties as working fluids: low critical temperature and pressure, small specific volume, low viscosity and surface tension, and high thermal conductivity $[14,15]$. Several studies show that the selection of working fluid is crucial to achieve the highest efficiency of the cycle. Some proposed selection criteria are: toxicity, flammability, cost, and thermal stability [16,17]. The main advantage in using organic working fluid is lower requested heat for fluid evaporation if compared with water; therefore, ORC turbines operate at lower temperatures and pressure than the conventional steam process $[18,19]$. Biomass-fuelled ORC plants coupled with $\mathrm{CHP}$, within the range 200-2000 $\mathrm{kW}_{\mathrm{e}}$, have been successfully designed and improved, as in the case of Admont $\left(400 \mathrm{~kW}_{\mathrm{e}}\right)$ and Lienz $\left(1000 \mathrm{~kW}_{\mathrm{e}}\right)$, in which silicon oil is used as a working medium and thermo-oil as a heating medium, achieving ca. $18 \%$ of electrical efficiency and $80 \%$ overall CHP efficiency [20,21]. Although small-scale and micro-scale biomass-fuelled ORC plants, coupled with CHP units, had less diffusion, there are several applications where energy needs of buildings were covered by an ORC turbine with less than $30 \mathrm{~kW}_{\mathrm{e}}$. These systems ensure an efficiency of about $15 \%$ in electricity and $60 \%-70 \%$ in heat $[22,23]$.

The Stirling engines present powerful characteristics for micro-CHP applications. An elementary Stirling engine system consists of an engine piston, an exchanger piston and three heat exchangers: a cooler, a regenerator, and a heater. The piston converts gas pressure into mechanical power, whereas the exchanger piston is used to move the working gas between the hot and cold sources. Stirling engines have the potential of achieving higher efficiencies because they closely approach the Carnot cycle. Currently, the engines are able to get an electrical efficiency of about $30 \%$ and a total efficiency of $85 \%-90 \%$. operating in cogeneration mode [24]. Stirling engines have been developed in a wide range of power capacities, from $1 \mathrm{~W}$ to $1 \mathrm{MW}$. The whole range of engines shows a great potential for combined heat and power systems. The kinematic Stirling units are able to produce from 1.1 to $500 \mathrm{~kW}_{\mathrm{e}}$ of power, while free piston Stirling engines can be found in the range between 1 and $25 \mathrm{~kW}_{\mathrm{e}}$ [25]. In a short review of the commercially available cogeneration systems, based on Stirling engines, there are several small units for residential and small-commercial use, which have the maximum electric power, from $1 \mathrm{~kW}$ to $3 \mathrm{~kW}$, and a thermal power from $7.5 \mathrm{~kW}$ to $30 \mathrm{~kW}$, ensured. For medium-sized users, it is possible to find engines with a maximum electric power of $30 \mathrm{~kW}$ and a thermal power of $90 \mathrm{~kW}$. The electric efficiency varies from a minimum of $12 \%$ to a maximum of $24 \%$ and the correlate range of thermal efficiency is above $72 \%-77 \%$ [26-28].

A short market and technology review shows that the Stirling engines are particularly suitable for small users and offer a great versatility of applications: an external combustion engine accepts several kind of heat source and fuels, from fossil to biomass, solar, geothermal, and nuclear [24]. An interesting application is a cogeneration system, based on a Stirling engine, which exploits solar radiation and biomass combustion at the same time: a fluidized bed combustor performs the biomass combustion and a Scheffler type mirror is adopted to concentrate solar irradiation in a fixed focal 
point. The total produced heat is converted into electricity by the Stirling engine, with a heat exchanger inserted directly into the biomass combustor [29].

\section{Experimental Section}

\subsection{The Biomass Plant Case of Study}

The CRB owns expertise on biomass plant design and monitoring [30,31]. Within the activities carried out by the research project ENERPOLL, funded by the Italian Ministry of Agriculture and Forestry, an innovative biomass plant for thermal energy, set in the rural facilities of S. Venanzo (TR) [32], was recently designed and improved.

The designed plant is the result of a detailed analysis of the territory in terms of biomass potential, energy requirements, and environmental problems affecting the rural companies set in the region. In particular, chicken livestock, for meat and egg production, is widely spread in the territory and every farm is affected by the difficulty of poultry manure disposal. This kind of sub-product, classified as biomass by regional law [33], is actually collected in sealed systems, according to the Municipality's city plan restraints regarding transportation and smell emissions. The manure is harvested in large bags and stored inside a dedicated rural facility building. Then, it can be disposed of, spread in fields as a fertilizer according to the nitrogen provision [34] and avoiding its nitro-poisoning. This regulation application, in preservation of groundwater purity, restricts the disposal of poultry manure as fertilizer, especially for livestock farms with few land extensions.

In the case study, a chicken company is characterized by huge thermal needs because of the high-quality egg production, exported for chicken reproduction, which imposes poultry houses with air conditioning systems. Due to functioning all the time, over the winter, and for the hot water production for eggs, and facilities frequently under cleaning, the total thermal requirement is around $165,000 \mathrm{kWh} /$ year. An environmentally friendly solution, which meets the needs of biomass disposal with the energy requirements of the company, is represented by a gasifier, fed by poultry manure. The produced syngas is burnt in a $300 \mathrm{~kW}$ thermal boiler in order to produce hot water $\left(75-80{ }^{\circ} \mathrm{C}\right)$ to feed the thermal terminal elements and hot water tanks, formerly heated by methane burners. Their substitution with a biomass boiler allows to obtain savings in carbon emissions and economic advantages.

The thermal plant is fed by poultry manure harvested from the livestock, consisting in 7 poultry houses, with a 6200 square-meter total extension, harvested in 1.2 cycles per year, for a total production of poultry manure around 1200 tons of wet weight per year. Poultry manure is composed by a little percentage of sawdust, used at every poultry cycle as bedding for chickens and providing a moisture between $12 \%-60 \%$. After a chicken cycle, biomass is harvested and stored in big bags raised by a crane and ripped one by one inside a mixer wagon. The mixer wagon provides a mechanical and thermal pretreatment of poultry manure. While the organic matter is mixed and homogenized by rotating blades, a thermal chamber wrapping the wagon is filled with hot water heated and pumped from an exchanger fed by the combustion gases. After the pretreatment, the biomass moisture level decreases to $12 \%-31 \%$ and it is loaded by a conveyor belt to a $6 \mathrm{~m}^{3}$ biomass storage tank.

The energy enhancement of the biomass pathway is composed of the storage tank, the gasifier and the thermal boiler, as shown below (Figure 1). From the tank the biomass is loaded to the gasifier from 
which it is conveyed, by a cochlea loading, a steady 0.15 cubic meters per hour. The gasifier is composed of an $80 \mathrm{~cm}$ internal radius cylinder, made of aluminum oxide, $25 \mathrm{~cm}$ in thickness, where the reached temperature is around $900 / 1000{ }^{\circ} \mathrm{C}$.

Due to the high thermal level reached, a sampling of syngas, using CRB instruments, was not possible. The lower heating value referred to dry sample of loaded biomass mix is in the range of $10-12 \mathrm{MJ} / \mathrm{kg}$ [32]. The magnitude of this range is in agreement with other literature values $[35,36]$.

The last section of the plant is represented by the thermal water distribution net, organized in piping systems to feed all the fan coils installed in the livestock buildings. The combustion gases are purified in dusts using cyclones and bag filters. Gaseous nitrogen compounds are currently monitored, and their concentration values are under the thresholds imposed by national regulations by biomass plants [13].

Figure 1. The biomass plant from the right side: the tank, the gasifier, and the boiler.

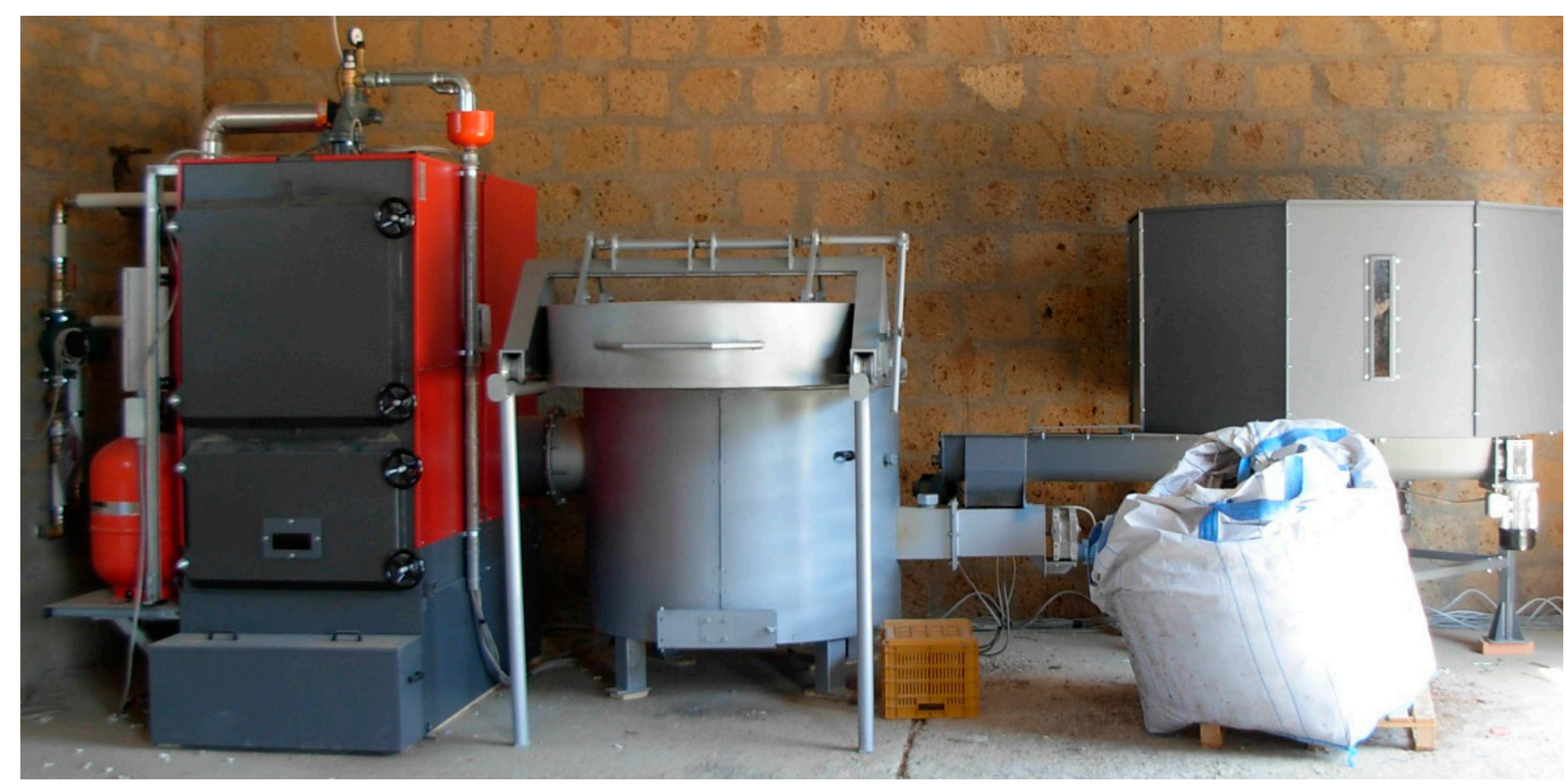

The widely oversized $300 \mathrm{~kW}$ thermal power of the boiler was chosen to not dispose of all the poultry manure produced by the livestock, and harvested, but to cover all the prompts of the plant and the energy requirements during the winter season where most of the energy losses from the livestock houses occur. Furthermore, the oversizing of the plant is attributable to the final predefined purpose of the project ENERPOLL [32] to complete the whole biomass pathway with the production of combined heat and power: due to the low conversion electric yield from heat, the chosen thermal power ensures a significant electric production.

\subsection{Italian Incentives on Electric Energy Production by Biomass Plants}

The Italian Decree on electric non-photovoltaics Renewables sources [37] was elaborated on by the Ministry of Environment, with the main goal to encourage the development of smaller plants for electrical production at the service of local territories/companies [38]. Therefore, incentive is given for electric energy, injected to the grid, at the net of electric plant auto-consumptions: generally, for biomass plants, a $17 \%$ is taken by national regulations [37]. This value was defined by legislators, 
considering the average power absorbed by all the features, both resistances and reactive utilities, necessary for the energy enhancement pathway. This value is consistent with the installed features, their electric power, and the assumed diversity factors for non-simultaneous operation.

The Decree on Renewables makes incentive also differentiated depending on the kind of biomass feeding the plant: biological biomass, such as from short rotation forestry or similar dedicated crops, by-products derived from farming and agricultural activities, or the organic fraction from wastes. Under the threshold of $300 \mathrm{~kW}$ powered plants, using sub-product biomass, the incentive is $0.257 €$ per electrical kWh [37].

The total yearly incentive, at the net of $17 \%$ of auto-consumption power, can be calculated as in the following Equation (1):

$$
\mathrm{I}=\mathrm{P} * 0.257 *(100 \%-17 \%) * \mathrm{~T}
$$

In which:

$\mathrm{I}=$ total yearly incentive $[€ /$ year $]$;

$\mathrm{P}=$ plant nominal power production $[\mathrm{kW}]$;

$\mathrm{T}=$ utilization time of electric production of the plant [h/year].

The incentive by energy production is applicable by authorization obtained for electric generation applications. When the installed plant is characterized by electric power under $50 \mathrm{~kW}$, with thermal energy cogeneration, it can be authorized with a simple Notice of Commencement of the intervention, presented to the local Municipality. If the electric power is below $200 \mathrm{~kW}$, the decree allows the installation permit through a simple communication in the case of integrated systems within the building so as not to modify the structural features, as happens in our case study of the plant [39].

Incentives aim at reducing operating costs for energy consumption, for example, for lighting (9000 kWh/year) in which CRB is experienced [40] because artificial lighting can simulate the sun cycle, twice per day, in order double the egg production.

\section{Results and Discussion}

\subsection{ORC Turbines Configuration}

Organic Rankine Cycle turbines have huge potential in electric production by thermal sources. This system is based on an organic substance as a working fluid in order to utilize low-grade heat sources, and it consists of an evaporator (heating area), a turbine, and a condenser (cooling area). Applications are encouraged by some positive aspects, such as the small size, no emissions of exhaust gases, such as carbon monoxide, carbon dioxide, nitrogen oxides, dusts, and other atmospheric pollutants, and its potential in applications with low-grade heat sources used for power generation [41].

Using a thermal oil for heat transfer, the working fluid is heated in the evaporator to be converted into a high-pressure vapor, expanding in the turbine producing mechanical energy converted into electricity via the generator connected to the turbine shaft. The vapor resulting from the turbine outlet is fed to the condenser, and, at the liquid phase, is recharged to the heater.

Generally, the most important parameters in a turbine plant are: the Turbine Inlet Temperature (TIT), the pressure ratio in the turbine and the mass flow rate. In the conventional plants, TIT is 
increased to improve the turbine output; however, this is not possible in low-grade heat-source applications, characterized by lower operational temperatures [42]. These are serious and difficult problems to overcome. Therefore, the organic substance selected as working fluid must have low latent heat and a high density.

\subsection{The Proposed System}

A detailed market analysis showed a particular matching of the biomass plant in S. Venanzo with a small-sized ORC turbine as the model PG15 [43]. This machine is particularly suitable to be coupled with biomass plants; Table 1 shows its main technical proprieties.

Table 1. Technical specifications of PG15, Organic Rankine Cycle (ORC) turbine [43].

\begin{tabular}{ll}
\hline Parameter & Value/Characteristic \\
\hline Electrical output & $15 \mathrm{~kW}$ \\
Energy input & $120-160 \mathrm{~kW}$ \\
Temperature inside evaporator & $70-95^{\circ} \mathrm{C}$ \\
Temperature inside condenser & $10-40^{\circ} \mathrm{C}$ \\
Heat transfer fluid & $\mathrm{r} 314$ \\
\hline
\end{tabular}

The selection of this model is related to the plant operative parameters: the syngas boiler is $300 \mathrm{~kW}$ of thermal power and a hot water flow of a maximum $70{ }^{\circ} \mathrm{C}$. To increase the outlet temperature, it is necessary to install a larger size boiler, working with pressurized water. The current proposed intervention for electric machine installation involves the existing plant: the change of the thermal boiler may be a possible future upgrade of the plant. However, the large outlet mass flow of thermal boiler (above $15 \mathrm{~m}^{3} / \mathrm{h}$ ) can be used to feed two, 15-electric powered ORC turbines, arranged in parallel, ensuring an electrical power of $30 \mathrm{~kW}$ with a thermal consumption of $240 \mathrm{~kW}$. The installation of a larger ORC machine is more efficient (i.e., the model ET30, $300 \mathrm{~kW}$ of thermal energy input and $30 \mathrm{~kW}$ of electrical output $[42,43]$ ) but it is not feasible. The minimum required temperature by the heat source is fixed in $86{ }^{\circ} \mathrm{C}$; but the biomass plant water boiler produces hot water at a maximum temperature of $70^{\circ} \mathrm{C}$.

The figure below summarizes the installed powers in the proposed configuration (Figure 2).

Figure 2. Power balance in the ORC turbine application to the biomass plant.

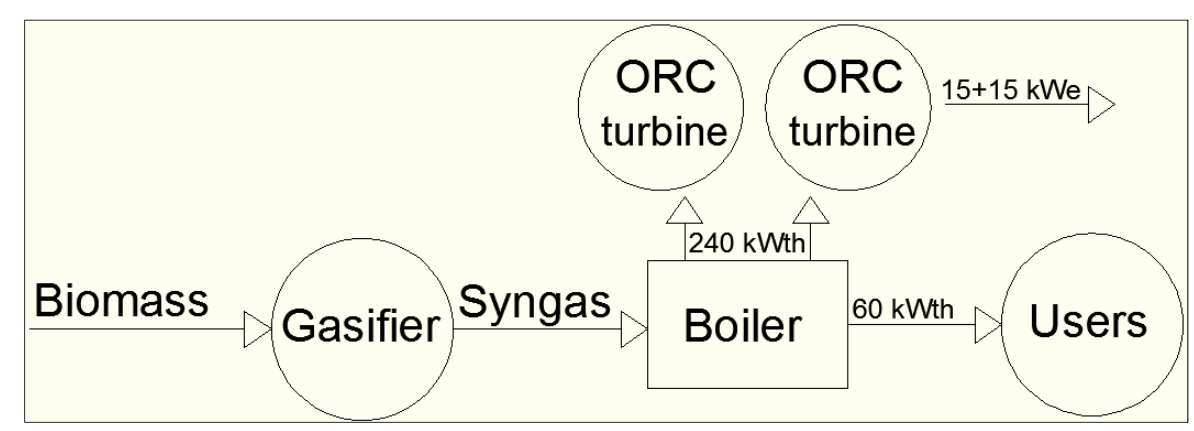




\subsection{The Economic and Performance Analysis}

The total $30 \mathrm{~kW}$ powered proposed machine configuration is designed for an operating time of $6400 \mathrm{~h} /$ year due to the current times for the maintenance of biomass pre-treatment, loading and storage features, especially the cochlea systems, subjected to frequent stress. Slightly higher operating times were computed in commercial ORC-biomass combined applications [42-44]. The total electric production is about 192,000 electric $\mathrm{kWh}$ /year. According to the national incentive on renewable electric production, at the net of auto-consumptions as explained in Equation (1), the total revenues are about $41 \mathrm{k} € /$ year for a duration of 20 years [37].

The total investment cost is $210 \mathrm{k} €$, including the cost for the hydraulic net (heat exchangers, piping, pumps and control systems) $[43,44]$. Operative costs are represented by the full maintenance service of the power plant and they are about $0.03 €$ per produced electric $\mathrm{kWh}$, for a total of $5800 € /$ year [45]. The costs for biomass collection operations, consisting of filling the big bags by a wheel loader and their displacement and storage inside the dedicated warehouse are not included: it is independent from the adopted electrical conversion technology analyzed in this paper.

The figure below summarizes the cash flow (revenues/costs) of the proposed assembled plant as a function of the incentive time (Figure 3), amounts have been made without counting interests on the investment and the depreciation.

Figure 3. Cash flow of ORC turbine application as a function of time (years).

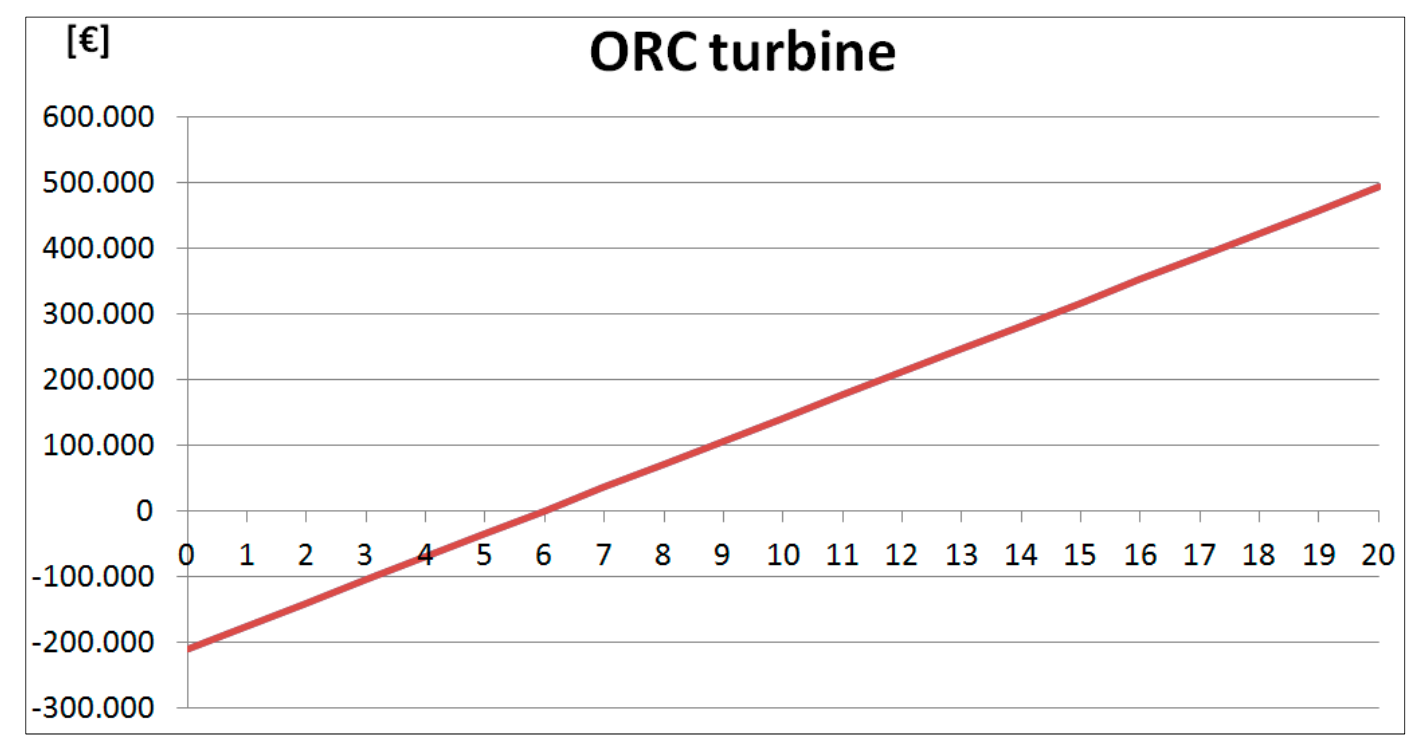

\subsection{Stirling Engine Configuration}

An interesting and different solution for electric production, coupled with a biomass plant, is represented by electric energy produced by a Stirling engine [46]. The external combustion characterizing the Stirling engines makes them very attractive for a small-scale CHP plant using bio-fuels. This kind of generator is based on a closed cycle, where the working fluid is alternately compressed in a cold cylinder and expanded in a hot cylinder volume [47].

The main advantage of Stirling engines, unlike internal combustion engines, is represented by the heat supply, not provided by a fuel combustion inside the cylinder, but transferred by a heat exchanger 
(heater) in the same way as in a steam boiler. Consequently, they can work on providing heat directly from the source, fed by a continuous combustion process and reducing the gaseous emissions caused by an intermittent combustion $[48,49]$. The thermal input is transferred from the external source to the working gas through a high temperature heat exchanger (between $950{ }^{\circ} \mathrm{C}$ and $1050{ }^{\circ} \mathrm{C}$ ); exchanged heat drives the pistons and, consequently, the shaft for the power production. The residual heat is recovered by the water circulation system. In order to obtain a high overall electric efficiency of the CHP plant, the temperature in the hot heat exchanger should be as high as possible; therefore, the preheating of the combustion air is provided by the heat recovered.

Dealing with applications of Stirling engines in biomass plants, it is possible to find several gasifier plants fed by biomass chips and pellet [46,50]. Different sizes are commercialized: four-engines plant with output/input of 140 electric kW/600 thermal kW in Denmark, operating for $7000 \mathrm{~h}$; two-engines 70 electric $\mathrm{kW} / 280$ thermal $\mathrm{kW}$ plant for Hospital in Hannover [50]. In Italy, a CHP prototype system in the Castel d'Aiano campus is a wood chips gasifier coupled with a Stirling engine. The raw biomass feeding is 450 tons/year; the thermal input power is about $200 \mathrm{~kW}$ and electric power is $35 \mathrm{~kW}$ for $6000 \mathrm{~h} /$ year of working time [51].

The plant configuration can be designed with the heater component of the Stirling machine, consisting in heat exchangers tubes, oriented and inserted to a gate at a side of the combustion chamber, in direct contact with the burning chamber volume, as described in the Lienz CHP plant in Austria, already experimented by Obernberger et al. (Figure 4). The heat exchanger is made of a metallic material, resistant to high temperatures produced by the combustion chamber $[26-28,42]$.

Figure 4. (a) The boiler (b) the insertion of the Stirling engine in the combustion chamber [42].
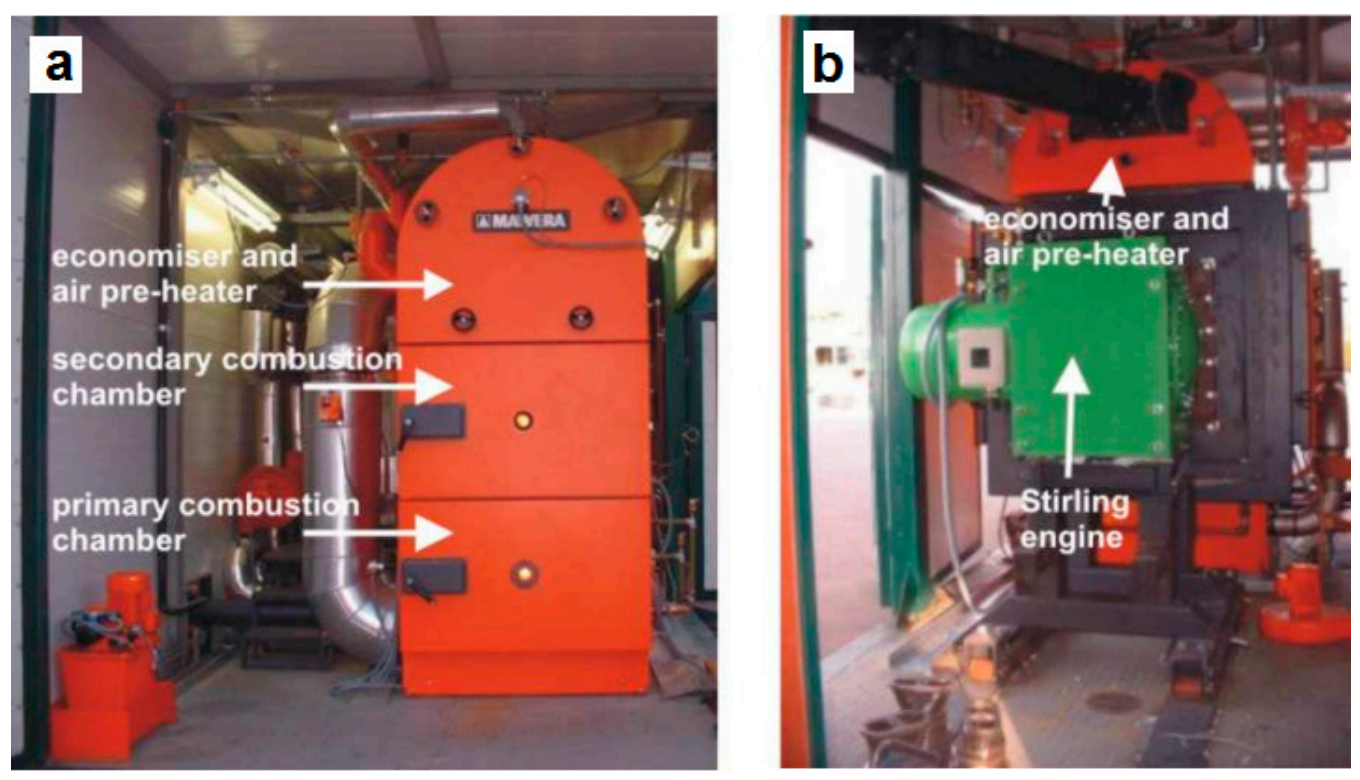

A similar application of Stirling engine to thermal plant to produce electricity was also experimented by Jai-Houng, where the engine was inserted into a hole through a biomass gasifier [52].

Due to the successful experiences, this application can be improved on for the poultry manure biomass plant, realized by $\mathrm{CRB}$, in S. Venanzo, and described in the previous paragraph. The below picture describes the proposed intervention in which the heat exchanger of the Stirling engine is inserted across the door of the boiler (Figure 5). 
Figure 5. The proposed intervention on the CRB biomass boiler and the particular of the heat exchanger, shown in section and in volumetric view [53].

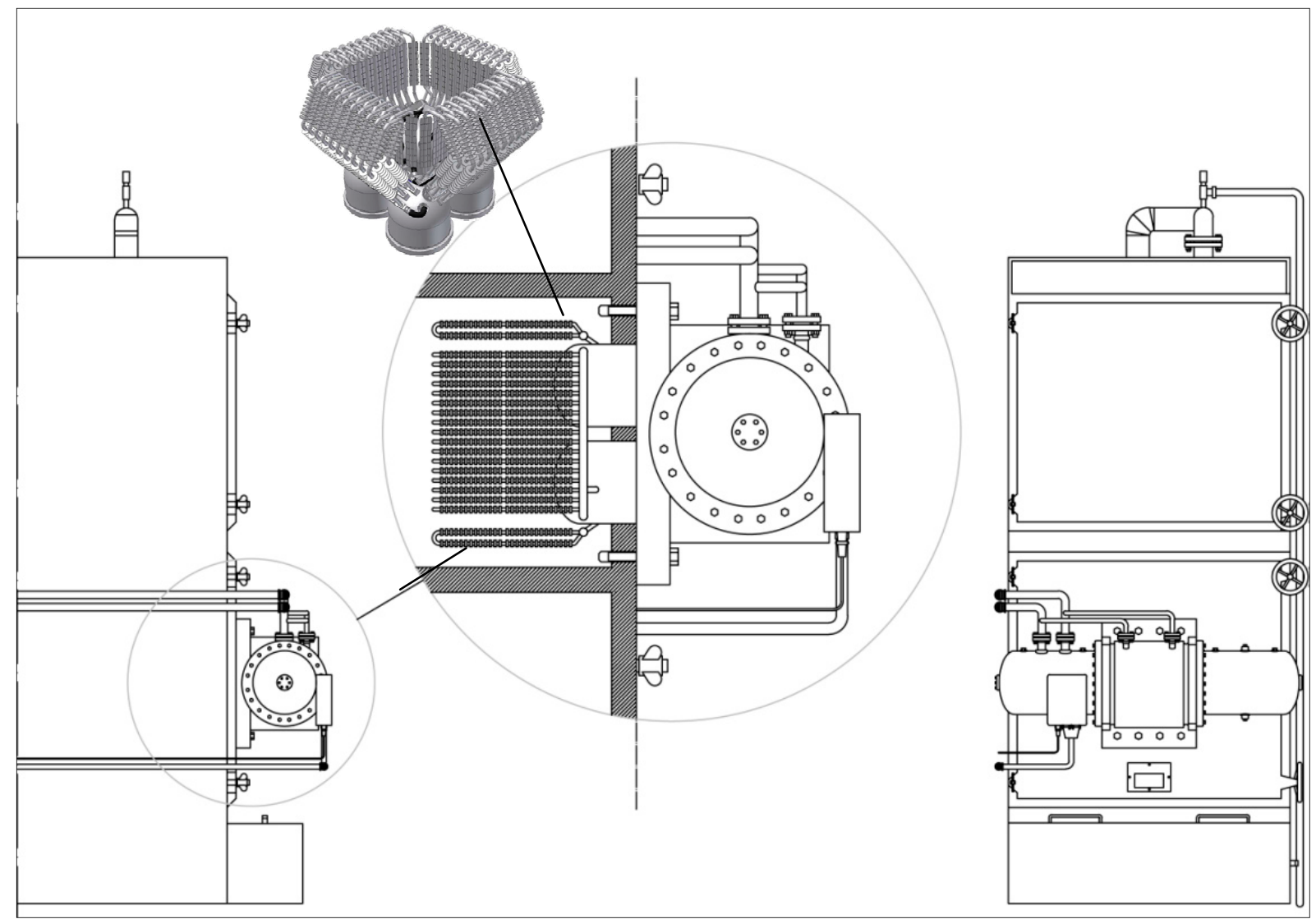

Lateral view Particular Frontal view.

\subsection{The Proposed System}

The proposed machine is a $35 \mathrm{~kW}$ electric powered "SD4-E" [53]. The engine is designed as a hermetically sealed unit with the alternator incorporated in a pressurized crankcase. Static seals are necessary between the helium working gas in the crank case and the air surrounding the surrounding system. All bearings are greased and the engine is oil-free. The internal design of the engine eliminates the need for high-pressure piston rod seals, which are known to cause problems in other Stirling engine configurations [26-28].

The engine, which is designed properly for CHP applications using biomass fuels, ensures a nominal electric power of $35 \mathrm{~kW}$, provided by four cylinders arranged in a square with the parallel cylinders [42]. Helium is used as working gas at 4,5 $\mathrm{MPa}$ maximum mean pressure. The four hot heat exchangers (one for each cylinder) are designed as panels forming a square combustion chamber, where radiation from the combustion is transferred directly to the panels. The hot exchangers consists of 23 steel tubes with an outside diameter of $13.7 \mathrm{~mm}$, a high temperature resistance of up to $1200{ }^{\circ} \mathrm{C}$, U-formed, and connecting the cylinder manifold with the regenerator manifold (see the particular in Figure 5) [50-53].

The table below (Table 2) summarizes the main characteristics of the chosen Stirling engine and the picture (Figure 6) shows the plant configuration once integrated with the Stirling machine. 
Table 2. Technical characteristics of $35 \mathrm{~kW}_{\mathrm{e}}$ "SD4-E", Stirling engine [50].

\begin{tabular}{ll}
\hline Parameter & Value/Characteristic \\
\hline No. of cylinders & 4 \\
Bore & $142 \mathrm{~mm}$ \\
Stroke & $76 \mathrm{~mm}$ \\
Working gas & Helium \\
Mean pressure & $4,5 \mathrm{MPa}$ \\
Engine speed & $1010 \mathrm{rpm}$ \\
Heat input & $200 \mathrm{~kW}$ \\
Heat output in water & $90 \mathrm{~kW}$ \\
Electric power output & $35 \mathrm{~kW}$ \\
Electrical efficiency & $17.5 \%$ \\
Nominal cooling water temperature & $55{ }^{\circ} \mathrm{C}$ \\
\hline
\end{tabular}

Figure 6. Power balance in the Stirling engine application to the biomass plant.

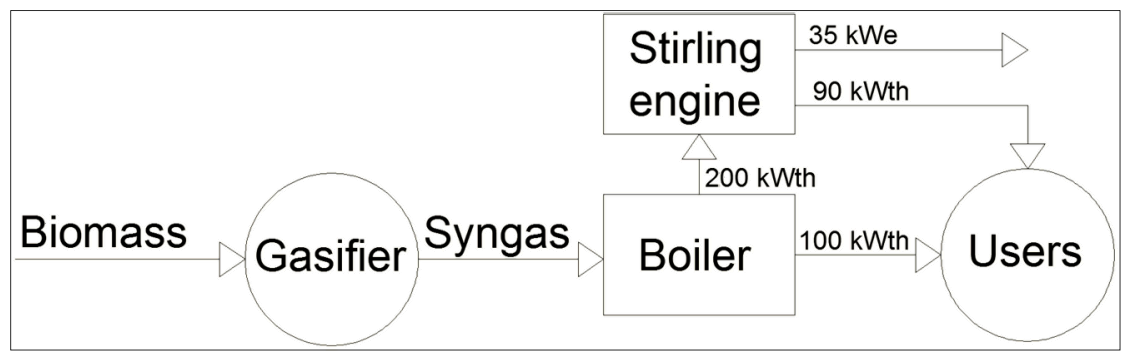

\subsection{The Economic and Performance Analysis}

The Figure below summarizes the cash flow of the proposed plant as function of time (Figure 7).

Figure 7. Cash flow of Stirling engine application as a function of time (years).

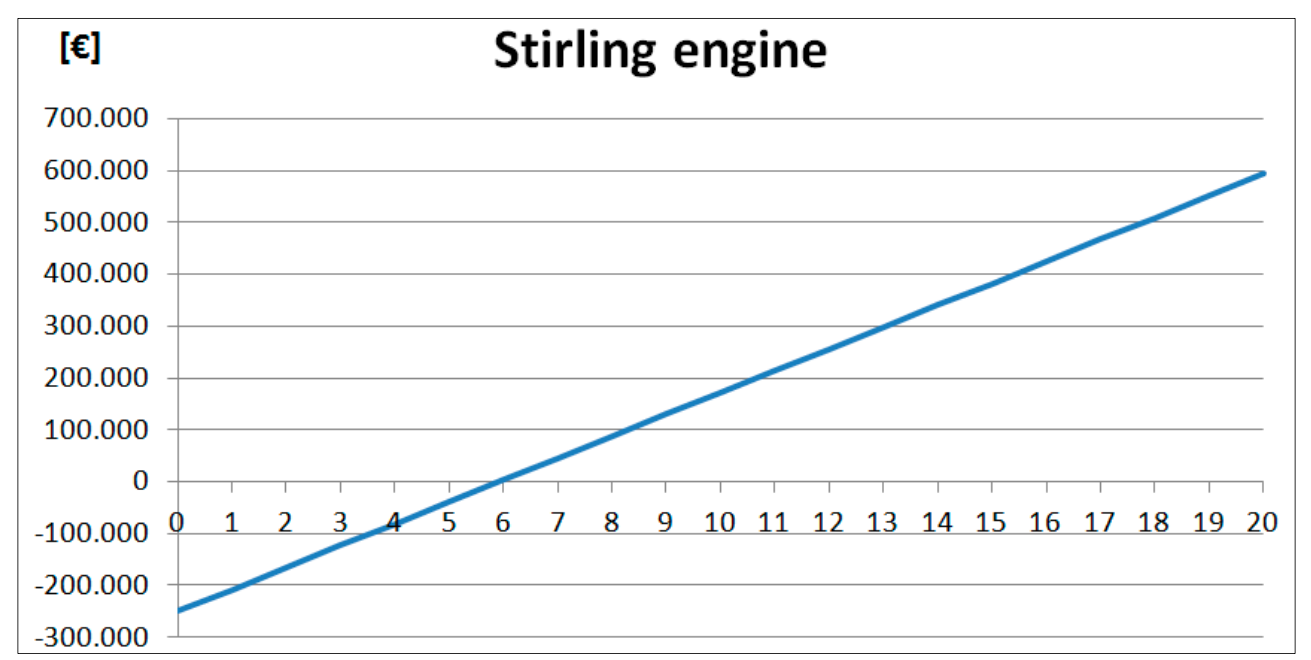

The investment cost for the $35 \mathrm{~kW}$ Stirling engine is about $250 \mathrm{k} €$. The operative costs, referred to a working time of 6,400 hours/year, compatible with the biomass boiler operating time, are $0.025 €$ per electric $\mathrm{kWh}$ produced [53], for a total amount of about $5600 € /$ year. The total revenues are calculated, as in Equation (1), and they are stabilized at about $48 \mathrm{k} € /$ year for a duration of 20 years [37]. 
Due to a correct comparison with the previous application, biomass-harvesting costs are not included and the investment costs have been considered without counting interests and depreciation.

\section{Conclusions and Future Prospects}

The pilot plant improved by CRB is a real example of a functioning plant powered by a particular biomass, the poultry manure, abundantly widespread on the territory and very problematic in terms of proper disposal. In addition to the manure disposing costs reduction, it is possible to produce heat and electric power from biomass and obtain incentives by energy selling to payback the investment costs.

This paper, within the ENERPOLL project research activities, aims at investigating about the state of the art of electric production applications to the existing biomass plant, analyzing two scenarios: via ORC turbines or via Stirling engines. The choice of the ORC turbine size is limited due to the low thermal level of the external source, imposing the installation of two $15 \mathrm{~kW}$ powered machines instead of only one turbine. The commercial market for Stirling engines identifies high performance for the $35-\mathrm{kW}$-powered machines. Therefore, the proposed electric upgrades of the biomass plant have the same working time and an equal installed electric power.

The cash flow analysis shows that the difference in investment cost is leveled by higher electric production and incentive amount in Stirling application; nonetheless the payback period of the investment for the electric upgrade is identified in the same year for both the applications. From a financial point of view, both the applications are equivalent.

The future prospects aims at analyzing other functional and logistic aspects (i.e., space occupancy, produced noise, thermal waste) to discriminate the applicationa. Furthermore, an Aspen modeling of both the ORC turbine and the Stirling machine will be carried out, coupled with the existing biomass plant. The thermal and pressures of involved fluids will be assessed precisely, simulating the performance and the limits of the whole plant. Business analysis of each component will be carried out by choosing the alternatives and assessing the useful life of each item so that it is compatible with the duration of the incentive.

The environmental benefits are mainly represented by the Carbon Emissions savings: thanks to the substitution of the methane burners with the biomass boiler for the 110,000 thermal $\mathrm{kWh} / \mathrm{year}$ production, allowing to avoid the production of 23 tons of carbon dioxide per year. Therefore, the injection into the grid, of about 215,000 electric $\mathrm{kWh}$ per year, aims at avoiding the total yearly amount of 105 tons of carbon released to the atmosphere by traditional thermal power plants.

\section{Acknowledgments}

The authors would like to acknowledge the "Cerquaglia livestock and country house" for their availability to jointly develop the research.

\section{Author Contributions}

Franco Cotana is scientific coordinator of the CIRIAF/CRB research group and he provided the research goals to be reached. Antonio Messineo is the coordinator of SINERGREEN project in which little sized Stirling engines are experimented. Gianluca Cavalaglio is the Biomass Laboratory responsible, 
where the biomass mixture was tested, helped by the Ph.D. student Andrea Aquino. Valentina Coccia, Alessandro Petrozzi and wrote a part of the context background and the research results.

\section{Conflicts of Interest}

The authors declare no conflict of interest.

\section{References}

1. European Commission. Communication from the Commission to the European Parliament, the Council, the European Economic and Social Committee and the Committee of the Regions: A Policy Framework for Climate and Energy in the Period from 2020 to 2030. Available online: http://eur-lex.europa.eu/legal-content/EN/TXT/?uri=CELEX:52014DC0015 (accessed on 12 August 2014).

2. European Commission. Directive 2009/28/EC of the European Parliament and of the Council of 23 April 2009 on the promotion of the use of energy from renewable sources and amending and subsequently repealing Directives 2001/77/EC and 2003/30/EC (Text with EEA relevance). Available online: http://eur-lex.europa.eu/legal-content/EN/TXT/?uri=CELEX:32009L0028 (accessed on 12 August 2014).

3. De Vos, R.; van Breevoort, P.; Höhne, N.; Winkel, T.; Sachweh, C. Assessing the EU 2030 Climate and Energy Targets. A Briefing Paper. Available online: http://www.ecofys.com/files/ files/ecofys-2014-assessing-the-eu-2030-targets.pdf (accessed on 12 August 2014).

4. Cotana, F.; Cavalaglio, G.; Bartocci, P.; Rinaldi, S.; Merico, M.C. First Activities of European Project "BEN": Biomass Energy Register for Sustainable Site Development for European Regions. In Proceedings of 18th Biomass Conference and Exhibition, Lyon, France, 3-7 May 2010.

5. Dong, L.; Liu, H.; Riffat, S. Development of Small-Scale and Micro-Scale Biomass-Fuelled CHP Systems-A literature review. Appl. Therm. Eng. 2009, 29, 2119-2126.

6. Maraver, D.; Sin, A.; Royo, J.; Sebastian, F. Assessment of CCHP systems based on biomass combustion for small-scale applications through a review of the technology and analysis of energy efficiency parameters. Appl. Energy 2013, 102, 1303-1313.

7. Xu, J.; Sui J.; Li, B.; Yang, M. Research, development and the prospect of combined cooling, heating, and power systems. Energy 2010, 35, 4361-4367.

8. Denntice d'Accacia, M.; Sasso, M.; Sibilio, S.; Vanoli, L. Micro-Combined Heat and Power in Residential and Light Commercial Applications. Appl. Therm. Eng. 2003, 23, 1247-1259.

9. Weiland, P. Biogas production: current state and perspectives. Appl. Microbiol. Biotechnol. 2010, 85, 849-860.

10. Kroiss, H. Anaerobe Abwasserreinigung. Wien. Mitt. 1985, 62, 65-68.

11. Dong, X.; Tollner, E.W. Evaluation of Annamox and denitrification during anaerobic digestion of poultry manure. Bioresour. Technol. 2003, 86, 139-145.

12. Leppälahti, J.; Koljonen, T. Nitrogen evolution from coal, peat and wood during gasification: Literature review. Fuel Process. Technol. 1995, 43, 1-45.

13. Decreto Legislativo 3 aprile 2006, n. 152. "Norme in materia ambientale". Available online: http://www.camera.it/parlam/leggi/deleghe/06152dl.htm (accessed on 12 August 2014). (In Italian) 
14. Papadopoulos, A.; Stijepovic, M. On the systematic design and selection of optimal working fluids for organic Rankine cycles. Appl. Therm. Eng. 2010, 30, 760-769.

15. Hung, T.C.; Wang, S.K.; Kuo, C.H.; Pei, B.S.; Tsai, K.F. A study of working fluids on system efficiency of an ORC using low-grade energy sources. Energy 2010, 35, 1403-1411.

16. Facao, J.; Oliveira, A.C. Analysis of Energetic, Design and Operational Criteria when Choosing an Adequate Working Fluid for Small ORC System. In Proceedings of the ASME 2009 International Mechanical Engineering Congress \& Exposition, Lake Buena Vista, FL, USA, 13-19 November 2009.

17. Quoilin, S.; van Den Broek, M.; Declaye, S.; Dewallef, P.; Lemort, V. Techno-economic survey of organic Rankine cycle (ORC) system. Renew. Sustain. Energy Rev. 2013, 22, 168-86.

18. Uris, M.; Linares, J.I.; Arenas, E. Techno-economic feasibility assessment of a biomass cogeneration plant based on an Organic Rankine Cycle. Renew. Energy 2014, 66, 707-713.

19. Oberberger, I. Decentralized Biomass Combustion: State of the Art and Future Development. Biomass Bioenerg. 1998, 14, 33-56.

20. Obernberger, I. Fuzzy Logic Controlled CHP Plant for Biomass Fuels based on Highly Efficient ORC Process. Available online: http://www.bios-bioenergy.at/uploads/media/Report-ORCLienzThermie-2003-08-29.pdf (accessed on 12 August 2014).

21. Obernberger, I. Biomass CHP Plant Based on an ORC Process-Realized EU-Demonstration Project in Admont/Austria. In Proceedings of the Meeting of IEA Bionergry, TASK 19 Biomass Combustion, Broadbeach, Australia, 6-8 December 2000.

22. Hao, L.; Guoquan, Q.; Yingjuan, S.; Daminabo, F.; Saffa, N.R. Preliminary experimental investigations of a biomass-fired micro-scale CHP with organic Rankine cycle. Int. J. Low Carbon Tech. 2010, 5, 81-87.

23. Algieri, A.; Morrone, P. Energetic analysis of biomass-fired ORC systems for micro-scale combined heat and power (CHP) generation. A possible application to the Italian residential sector. Appl. Therm. Eng. 2013, doi:10.1016/j.applthermaleng.2013.11.024.

24. Ferreira, A.C.M.; Nunes, L.M.; Martins, L.A.S.B.; Teixeira, F.C.F.S. A Review of Stirling Engine Technologies applied to micro-Cogeneration System. In Proceedings of ECOS 2012-The 25th International Conference on Efficiency, Cost, Optimization, Simulation and Environmental Impact of Energy Systems, Perugia, Italy, 26-29 June 2012.

25. Formosa, F.; Despesse G. Analytical model for Stirling cycle machine design. Energy Convers. Manag. 2010, 51, 1855-1863.

26. WhisperGen CHP System form WisperTech Company Web Site. Available online: http://www.atetsrl.it/wp-content/uploads/2011/03/Specifica-tecnica-EU1_IT.pdf (accessed on 12 August 2014). (In Italian)

27. Baxi Group and De Dietrich Remeha Group official Web Site. Available online: http://www.bdrthermea.com/micro-chp/ (accessed on 12 August 2014).

28. Stirling BioPower Web Site. Available online: http://www.sp-usa.com/faq/ (accessed on 15 August 2014).

29. Angrisani, G.; Bison, K.; Chirone, R.; Continillo, G.; Fusco, G.; Lombardi, S.; Marra, F.S.; Miccio, F.; Roselli, C.; Sasso, M.; et al. Development of a new concept solar-biomass cogeneration system. Energy Convers. Manag. 2013, 75, 552-560. 
30. Cotana, F.; Petrozzi, A.; Pisello, A.L.; Cavalaglio, G.; Coccia, V.; Moretti, E. An innovative small sized anaerobic digester integrated in historic building. Energy Proced. 2013, 45, 333-341.

31. Beatrice, C.; di Blasio, G.; Lazzaro, M.; Cannilla, C.; Bonura, G.; Frusteri, F.; Asdrubali, F.; Baldinelli, G.; Presciutti, A.; Fantozzi, F.; et al. Technologies for energetic exploitation of biodiesel chain derived glycerol: Oxy-fuels production by catalytic conversion. Appl. Energy 2013, 102, 63-71.

32. Cotana, F.; Coccia, V.; Petrozzi, A.; Cavalaglio, G.; Gelosia, M.; Merico, M.C. Energy valorization of poultry manure in a thermal power plant: Experimental campaign. Energy Proced. 2013, 45, 323-332.

33. Regolamento Regionale 4 maggio 2011, n. 4. Available online: http://www.gazzettaufficiale.it/ eli/id/2011/06/11/011R0245/s3 (accessed on 12 August 2014). (In Italian)

34. Council Directive 91/676/EEC of 12 December 1991 Concerning the Protection of Waters Against Pollution Caused by Nitrates from Agricultural Sources. Available online: http:/eur-lex.europa.eu/ LexUriServ/LexUriServ.do?uri=CELEX:31991L0676:EN:HTML (accessed on 12 August 2014).

35. Billen, P.; Costa, J.; van der Aa, L.; Caneghem, J.V.; Vandecasteele, C. Electricity from poultry manure: a cleaner alternative to direct land application. J. Clean. Prod. 2014, doi:10.1016/j.jclepro.2014.04.016.

36. Ahn, H.K.; Richard, T.L.; Choi, H.L. Mass and thermal balance during composting of a poultry manure. Wood shavings mixture at different aeration rates. Process. Biochem. 2007, 42, 215-223.

37. Italian Decree on Non-photovoltaic Renewables: D.M. 06/07/2012. Available online: http://www.sviluppoeconomico.gov.it/images/stories/normativa/DM_6_luglio_2012_sf.pdf (accessed on 12 August 2014). (In Italian)

38. Messineo, A.; Volpe, R.; Asdrubali, F. Evaluation of Net Energy, Obtainable from Combustion of Stabilised Olive Mill By-Products. Energies 2012, 5, 1384-1397.

39. Italian Decree on Renewable Energy Plants Authorization: D.M. 10-09-2010. Available online: http://www.provincia.milano.it/export/export_14032014/n_energia_2010_DM_Sviluppo_Economic o_10_09_2010.pdf (accessed on 12 August 2014). (In Italian)

40. Pisello, A.L.; Castaldo, V.L.; Taylor, J.E.; Cotana, F. Expanding Inter-Building Effect modeling to examine primary energy for lighting. Energy Build. 2014, 76, 513-523.

41. Yamamoto, T.; Furuhata, T.; Arai, N.; Mori, K. Design and testing of Organic Rankine Cycle. Energy 2001, 26, 239-251.

42. Obernberger, I.; Carlsen, H.; Biedermann, F. State-of-the-Art and Future Developments Regarding Small-Scale Biomass CHP Systems with a Special Focus on ORC and Stirling Engine Technologies. Available online: http://turboden.eu/en/public/downloads/small_scale_CHP_ technologies.pdf (accessed on 12 August 2014).

43. AGRAS ENERGIA. Available online: http://www.exaenergie.com/index.php?option=com_content\& view $=$ article $\& i d=65 \&$ Itemid $=139$ (accessed on 12 August 2014). (In Italian)

44. Peretti, I. Application of ORC units in sawmills. Technical-economic consideration. Available online: http://www.turboden.eu/en/public/downloads/08A03722_paper_turboden_segherie.pdf (accessed on 12 August 2014) 
45. Politecnico di Milano, Dipartimento di Energia. Costi di produzione di energia elettrica da fonti rinnovabili. Available online: http://www.autorita.energia.it/allegati/docs/11/103-11arg_rtalla.pdf (accessed on 12 August 2014). (In Italian)

46. Podesser, E. Electricity production in rural villages with a biomass Stirling Engine. Renew. Energy 1999, 16, 1049-1052.

47. Thombare, D.G.; Verma, S.K. Technological development in the Stirling cycle engines. Renew. Sustain. Energy Rev. 2008, 12, 1-38.

48. Walker, G. Stirling Engines; Clarendon Press: Oxford, UK, 1980.

49. Kongtragool, B.; Wongwises, S. A Review Of Solar-Powered Stirling Engines and Low Temperature Differential Stirling Engines. Renew. Sustain. Energy Rev. 2003, 7, 131-154.

50. WUDAG. Available online: http://www.stirling-energie.de (accessed on 31 July 2014). (In German)

51. CISA, COSEA. The Ecological Plant in Castel d'Aiano-The CHP System of Castel d'Aiano School Campus: Wood Chips Gasification and Stirling Engine. Available online: http://www.centrocisa.it/materiale/pubblicazioni/CasteldAiano_inglese.pdf (accessed on 12 August 2014).

52. Jai-Houng, L. Biomass power generation through direct integration of updraft gasifier and Stirling engine combustion system. Adv. Mech. Eng. 2010, doi:10.1155/2010/256746.

53. Stirling Danmark Catalog. Stirling Engines for Biomass Applications. Available online: http://elmiraohio.com/Gasifier (accessed on 31 July 2014).

(C) 2014 by the authors; licensee MDPI, Basel, Switzerland. This article is an open access article distributed under the terms and conditions of the Creative Commons Attribution license (http://creativecommons.org/licenses/by/3.0/). 